\title{
Optimal kinematic design of a multi-link steering system for a bus independent suspension: An application of response surface methodology
}

\author{
M.M. Topaç*, U. Deryal**, E. Bahar***, G. Yavuz**** \\ *Faculty of Engineering, Dokuz Eylül University, 35397 Izmir, Turkey, E-mail: murat.topac@deu.edu.tr \\ **Faculty of Engineering, Dokuz Eylül University, 35397 Izmir, Turkey, E-mail: ugur.deryal@ogr.deu.edu.tr \\ ***Faculty of Engineering, Dokuz Eylül University, 35397 Izmir, Turkey, E-mail: egemen.bahar@ogr.deu.edu.tr \\ ****Hexagon Studio, TOSB 1.Cadde 15.Yol No: 7, 41420, Kocaeli, Turkey, E-mail: Guven.Yavuz@hexagonstudio.com.tr
}

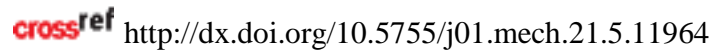

\section{Nomenclature}

$\beta_{F}$-steering error; $\beta_{L}$-steering angle of the wheel; $\beta_{S}$-steering wheel angle; $\beta_{V}$-toe angle; CCD - central composite design; DSA - design sensitivity analysis; $e_{L}$ - unit vector of the steering axis; $e_{Y R}$ - unit vector of the wheel rotation axis; FFD - full factorial design; $L_{F}$ - wheelbase, mm; MSE - maximum steering error, ${ }^{\circ}$; $O$ - centre of the bend; $S_{A}$ - centre of gravity of the vehicle body; $s_{R}$ - track width, mm; SS - sweep study; $\Delta z_{A 8}$ - wheel displacement, $\mathrm{mm}$

\section{Introduction}

Through their design simplicity and ease of manufacturing, Ackerman trapezoidal linkage has a broad application area as the steering system of heavy commercial vehicles equipped with solid axles. On the other hand, as a result of the comfort and control requirements, one of the main targets to be reached in the design of vehicle suspensions is to keep the unsprung mass as small as possible. In order to satisfy these demands, independent front suspensions (IFS) are applied increasingly on busses and trucks by the heavy commercial vehicle manufacturers [1]. In this case, more sophisticated systems are demanded to meet the sufficient steering and independent wheel travel functions simultaneously. Because of its design advantages, multilink steering linkage (or "opposed four-bar linkage" [2, 3]) is used in the majority of the passenger busses equipped with IFS. This mechanism basically consists of two relay levers, one track rod, two tie rods and two steering arms as seen in Fig. 1.

Kinematic model of a typical bus IFS including

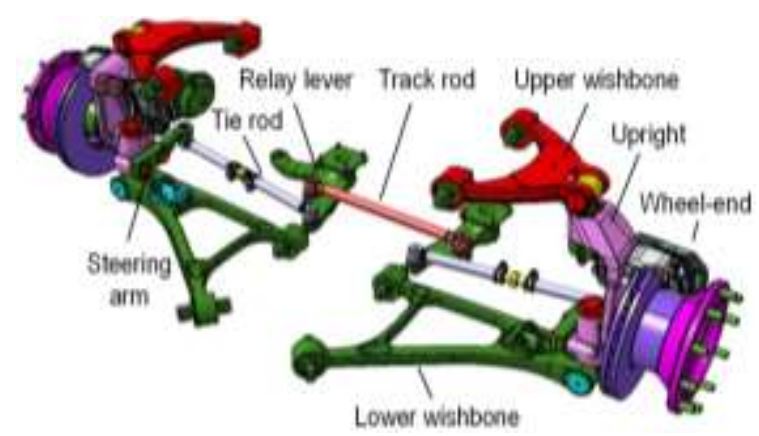

Fig. 1 General view of a bus IFS with the multi-link steering linkage the multi-link steering linkage is also seen in Fig. 2. Here, $A_{8}$ is the centre of mass of the wheel assembly. $A_{7}$ is the intersection point of steering axis and wheel rotation axis which are described by the unit vectors $e_{L}$ and $e_{Y R}$ respectively. The co-ordinate system $x-y-z$ is described at the vehicle body centre of gravity $S_{A}$. As can be seen from this model, the relay levers are attached to the vehicle body via revolute joints $\mathrm{A}_{14}$. Transmission of the rotational motion between the relay levers is provided by a track rod which is mounted to the relay levers with spherical joints $A_{13}$. In majority of the busses, assembly of the relay levers and the track rod is planar. Tie rod is also connected to steering arm and relay lever spatially via spherical joints $A_{9}$ and $A_{10}$ respectively.

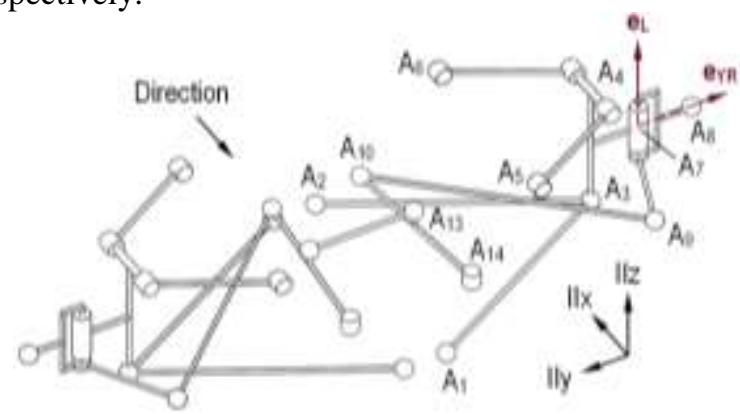

Fig. 2 Kinematic model of the IFS and steering linkage

Generally, one of the main requirements of a vehicle steering mechanism is to give to the steerable wheels a correlated $\beta_{L}$ such that, the intersection of the wheel axes should meet at the centre of the bend, $O[3,4]$. This rule which can also be seen for a two axle vehicle in Fig. 3 is known as "Ackermann Principle".

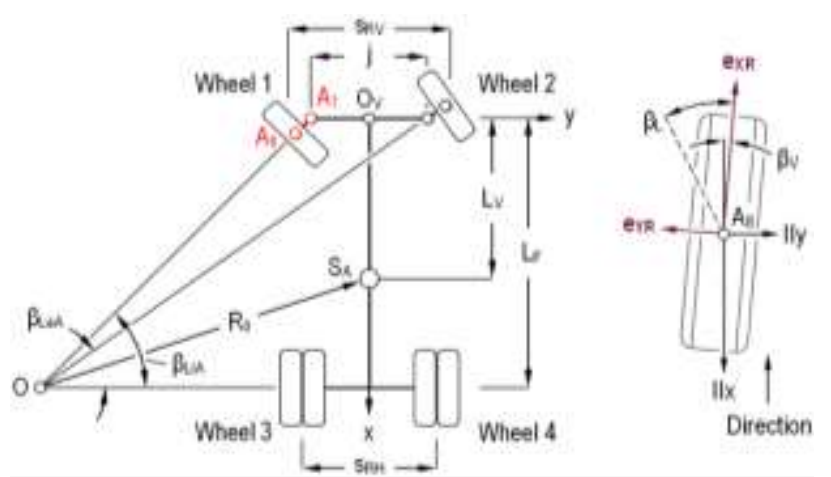

Fig. 3 Ackermann steering geometry and $\beta_{V}$ angle of the wheel 1 

pressed as:

Mathematically, Ackermann principle can be ex-

$$
\beta_{L a A}\left(\beta_{L i}\right)=\tan ^{-1} \frac{1}{\cot \beta_{L i}+\frac{j}{L_{F}}},
$$

where $\beta_{L a}$ is the steering angle of the outer wheel and $\beta_{L a A}$ is the ideal turning angle which is obtained from Eq. (1) for a given steering angle $\beta_{L i}$ of the inner wheel. The deviation $\beta_{F}$ between the ideal steering angle and real turning angle of the wheel which is caused by the steering mechanism geometry is called "the steering error" or "Ackermann error". Basically, a steering mechanism should satisfy Ackermann principle for given steering error tolerances. $\beta_{F}$ can be written as:

$$
\beta_{F}\left(\beta_{L i}\right)=\beta_{L a}\left(\beta_{L i}\right)-\beta_{L a A}\left(\beta_{L i}\right) .
$$

The spatial position of the tie rod of a multi-link steering system also affects the toe $\left(\beta_{V}\right)$ deviation of the wheel (Fig. 3) as well as MSE. Hence, during the kinematic design process of a multi-link steering mechanism, the deviation of $\beta_{V}$ caused by the wheel travel should also be taken into account.

In literature, there are some published works on kinematic optimisation of the steering systems. Zhou et al. optimised a rack-and-pinion steering mechanism by combining MATLAB genetic algorithm toolbox with MSC. Adams ${ }^{\circledR}$ to improve steering and $\beta_{V}$ characteristics [5]. Hanzaki et al. performed the combined kinematic and sensitivity optimisation of a rack-and-pinion steering linkage used in passenger cars [6]. Oz et al. presented a model validation methodology and the optimisation study on the hardpoints of solid axle suspension and steering systems of a heavy commercial vehicle by using Design of Experiments DOE approach [7]. Liang and Xin optimised the toe deviation of a double wishbone suspension during vertical wheel travel via Adams/View [8]. An interesting paper was published by Kim et al. on the effect of the drag link hardpoints on $\beta_{V}$ angle and the deviation of the wheelbase for a solid front axle. In their work, they used a $L_{27}\left(3^{13}\right)$ type orthogonal array and ANOVA to obtain the optimal combination of design parameters [9]. In open literature, to date and to the best of the authors' knowledge there have been a few works published on the kinematic optimisation the multi-link steering mechanisms for independent suspensions. Bian et al. established the multibody model of the steering mechanism based on the R-W (Robertson and Wittenburg) method for the MacPherson strut [10] and double wishbone suspension [11] for automobiles. In these two works, the suggested models are identical. In summary, all of these works mainly focalise on optimisation of the partial kinematic parameters of a steering system rather than presenting a complete optimization procedure.

In the present study, a response surface-based design procedure to build a multi-link steering system for a passenger bus IFS which satisfies optimum tolerances of $\beta_{V}$ and $\beta_{F}$ deviations is proposed. A brief summary of the method used in this work is seen in Fig. 4. In stage 1, a multibody model of a bus IFS including the steering mechanism was performed by using MSC. Adams ${ }^{\circledR}$ commercial software. In order to compose the IFS model, the hard- points $A_{1}$ to $A_{8}$ were drawn from a produced intercity bus. In this model, primary position of the tie rod and the position tolerances of the hardpoints $\mathrm{A}_{9}$ and $\mathrm{A}_{10}$ were chosen by considering the design limitations such as the brake system and the knuckle design. In stage 2, optimal positions of $\mathrm{A}_{9}$ and $\mathrm{A}_{10}$ which directly affect the $\beta_{V}$ angle of the front wheels during the wheel travel were determined by using DOE approach via Adams/Insight ${ }^{\mathrm{TM}}$ multi-objective optimisation tool. To this end, firstly the most important factors among the Degrees of Freedom (DOF) of $\mathrm{A}_{9}$ and $\mathrm{A}_{10}$ on $\beta_{V}$ deviation were chosen via a factorial designbased DSA. Results obtained from FFD study were utilised in MINITAB $^{\circledR}$, a practical stastistical software package [12]. In order to find out the exact optimum locations of $\mathrm{A}_{9}$ and $\mathrm{A}_{10}, \mathrm{CCD}$ was also utilised. By using the results, the vertical position of the multi-link mechanism plane was also determined. In stage 3, which is the final phase, MSE was optimised in the $\beta_{L}$ range of the front wheels by taking Ackermann principle into account. For this reason, an $\mathrm{H}-$ shaped parallel arm mechanism which is the most general from was chosen as the base model for optimisation study. Optimal positions of the hardpoints $\mathrm{A}_{10}, \mathrm{~A}_{13}$ and $\mathrm{A}_{14}$ which constitutes the kinematic shape of the relay lever and directly affect the steering error is studied by using a composite method including SS and CCD.

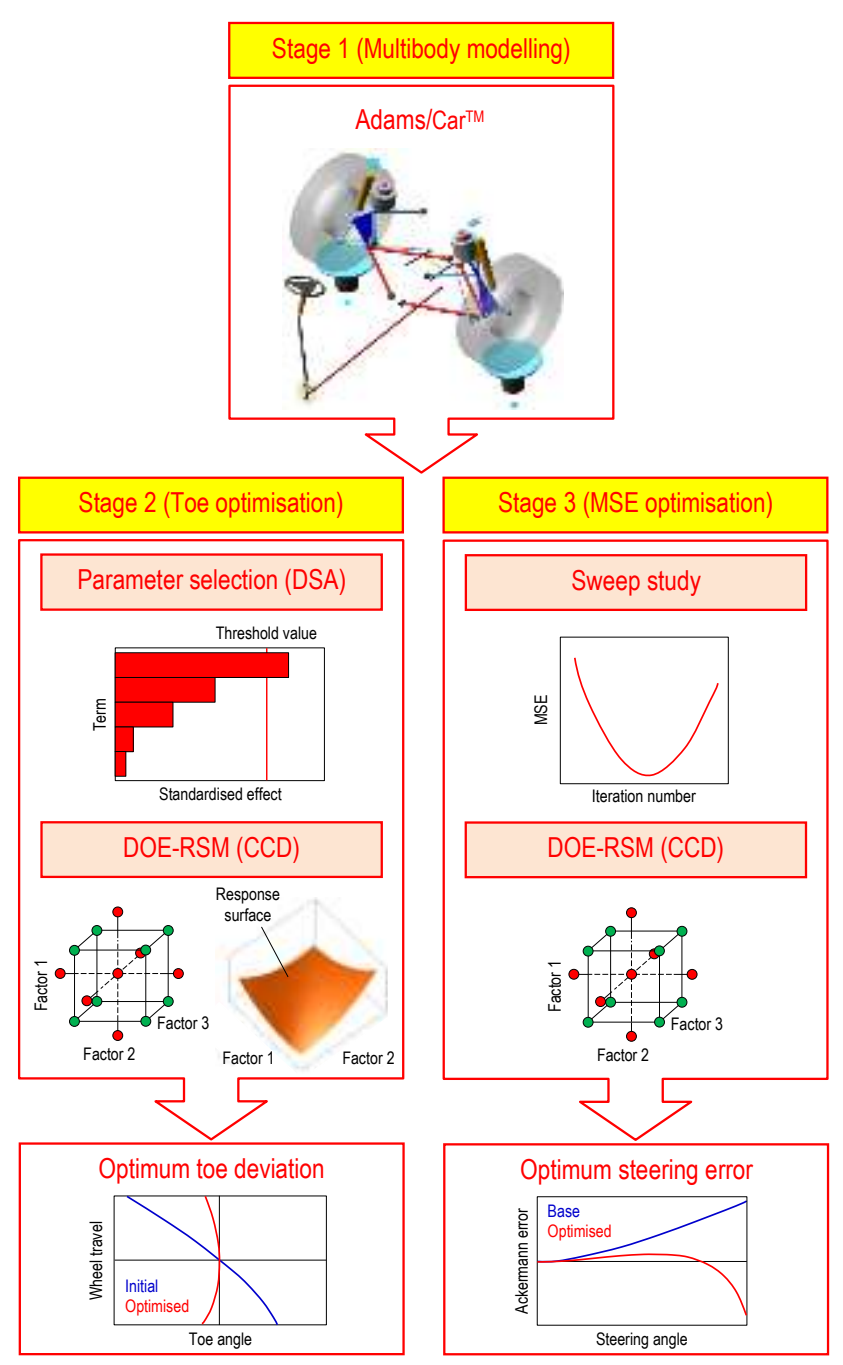

Fig. 4 Summary of the optimisation process 


\section{Multibody model of the double wishbone suspension}

A three dimensional multibody model of the bus IFS including the full steering system is composed by using Adams/CarTM module of MSC. Adams ${ }^{\circledR}$. In this model which is seen in Fig. 5, Adams/Car ${ }^{\mathrm{TM}}$ co-ordinate axis convention was applied [13]. Model consists of 15 elements. Kinematic constraint elements are also shown in Fig. 6. In this model, steering wheel 1 and steering column 2 are directly connected with the upper part of the intermediate shaft 3 via universal joint (U). A translational joint (T) which has single sliding DOF is defined between the upper and lower parts of the intermediate shaft. Lower part is also connected to the rack of the steering box 4 by a universal joint. Pitman arm 5 is fixed to the output shaft and also connected to the drag link 6 . The other end of drag link and track rod 8 is mounted to the relay lever 7 via spherical joints (S). In order to reduce the DOF and simplify the model, "Convel" homokinetic joint (C) which has 2 DOF is utilised instead of a 3 DOF spherical joint for relay lever-tie rod 9 connection $\left(\mathrm{A}_{10}\right)$. Steering arm 10 - tie rod connection is provided by a spherical joint.

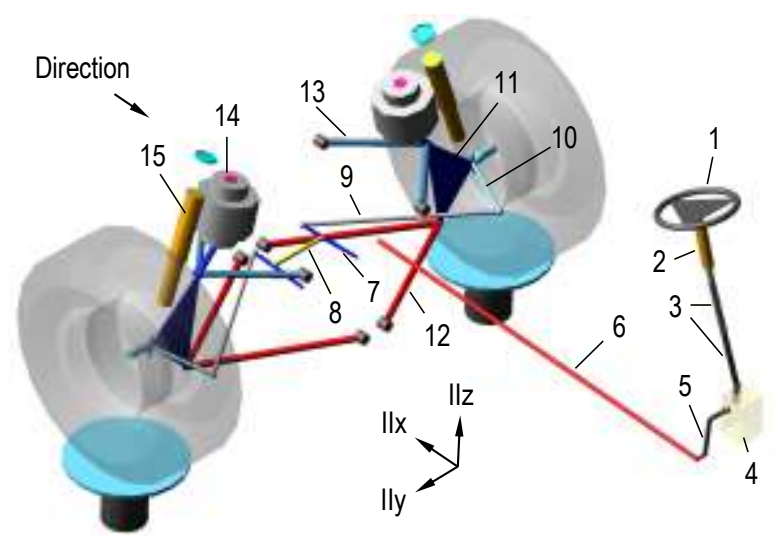

Fig. 5 Multibody model of the bus IFS and steering system

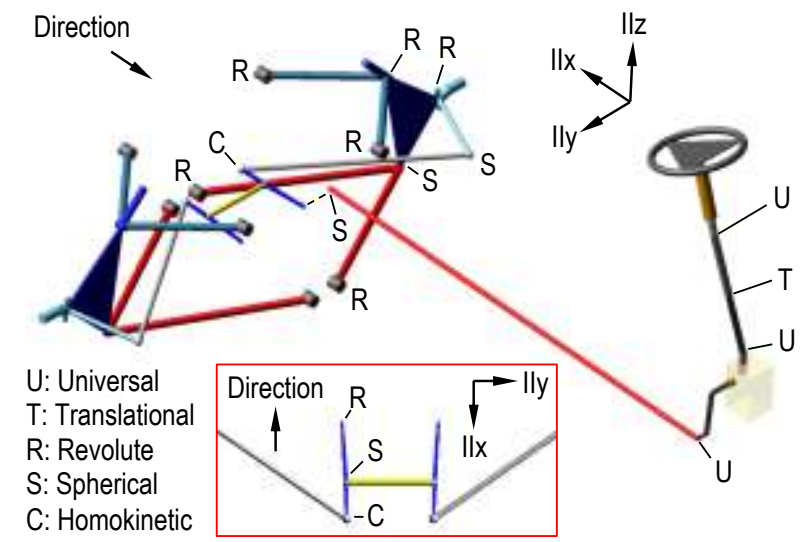

Fig. 6 Kinematic constraints of the steering mechanism

Steering axis is defined as the rotation axis of a revolute joint $(\mathrm{R})$ which is located on the upright 11 . Upright is also connected with upper 13 and lower 12 wishbones via revolute and spherical joints. Air spring 15 is directly mounted on upright instead of a wishbone. According to $[14,15]$ spring rate of the suspension can be assumed as $i_{F} \approx 1$ (-) for this design type. PAC2002 tyre model [16] was used for tyres with dimensions of 295/80 R 22.5 which is similar those fitted on the bus axles.

\section{Methodology}

In this study DOE-RSM methods are utilised to determine the optimum values of the parameters providing the desired ranges of $\beta_{V}$ deviation and $\beta_{F}$. Optimisation process was carried out by Adams/Insight ${ }^{\mathrm{TM}}$ which includes DOE and RSM tools. The DOE approach is used for understanding the correlation between the design parameters of the system and its performance [17]. Essentially, RSM is one of the extended DOE methods which uses a polinomial type regression model $y(x)$ [18]. Principal target of the response surface experiments is to obtain an appropriate model to estimate and analyse the relationship between design variables and system response. For a second order response surface model, the regression model is defined in general form as [19]:

$$
y=\beta_{0}+\sum_{i=1}^{k} \beta_{i} x_{i}+\sum_{i \leq j}^{k} \beta_{i j} x_{i} x_{j}+\varepsilon .
$$

Eq. (3) may also be written in terms of e.g. two variables as:

$$
y=\beta_{0}+\beta_{1} x_{1}+\beta_{2} x_{2}+\beta_{3} x_{1}^{2}+\beta_{4} x_{2}^{2}+\beta_{5} x_{1} x_{2}+\varepsilon .
$$

In order to linearise the regression model, new variables may be expressed as $x_{3}=x_{1}{ }^{2}, x_{4}=x_{2}{ }^{2}$ and $x_{5}=x_{1} x_{2}$. Hence, Eq. (4) can be written as:

$$
y=\beta_{0}+\beta_{1} x_{1}+\beta_{2} x_{2}+\beta_{3} x_{3}+\beta_{4} x_{4}+\beta_{5} x_{5}+\varepsilon .
$$

This model can also be expressed in matrix form for $M$ experiments as:

$$
y=X \beta+\varepsilon,
$$

where

$$
\begin{aligned}
& y=\left[y_{1}, y_{2}, \ldots, y_{M}\right]^{T} ; \\
& X=\left[\begin{array}{ccccc}
1 & x_{11} & x_{21} & \ldots & x_{51} \\
1 & x_{12} & x_{22} & \ldots & x_{52} \\
\ldots & \ldots & \ldots & \ldots & \ldots \\
1 & x_{1 M} & x_{2 M} & \ldots & x_{5 M}
\end{array}\right] ; \\
& \beta=\left[\beta_{0}, \beta_{1}, \beta_{2}, \beta_{3}, \beta_{4}, \beta_{5}\right]^{T} ; \\
& \varepsilon=\left[\varepsilon_{1}, \varepsilon_{2}, \ldots, \varepsilon_{M}\right]^{T},
\end{aligned}
$$

here $y$ is vector of observations, $X$ is the model matrix, $\beta$ is the vector which includes the interception parameter $\beta_{0}$ and the partial regression coefficients and $\varepsilon$ is the vector of random errors [20], the estimated value of $\beta$ which minimises $\varepsilon$ can be expressed as:

$$
\hat{\beta}=\left(X^{T} X\right)^{-1} X^{T} y
$$

ADAMS/Insight ${ }^{\mathrm{TM}}$ uses the method of least squares to estimate the $\beta$ coefficients in the regression model [21]. In this study, CCD type which is offered in the design specification table of Adams/Insight ${ }^{\mathrm{TM}}$ was utilised 
for this purpose. The CCD involves the use of a two-level factorial or fraction combined with $2 k$ axial or star points. Hence, the design includes factorial points, $2 k$ axial points, and total $n_{c}$ centre runs, yielding a total number of $2^{k}+2 k+n c$ runs are carried out to achieve experimental data. A comparison of the two level FFD and the CCD for three factors is seen in Fig. 7.

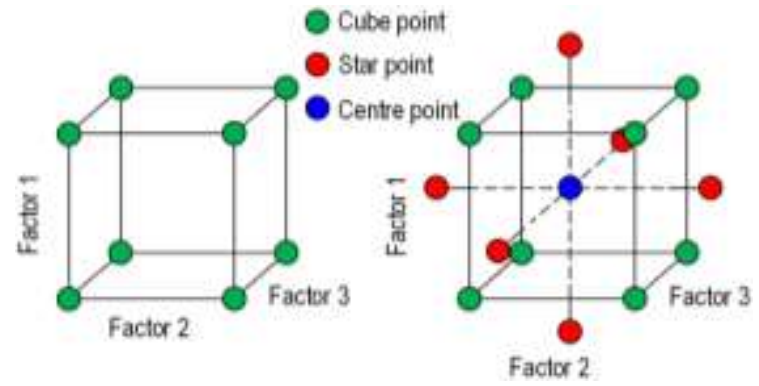

Fig. 7 Comparison of FFD and CCD (according to [17])

Fig. 8.

Methodology of the study is summarised in

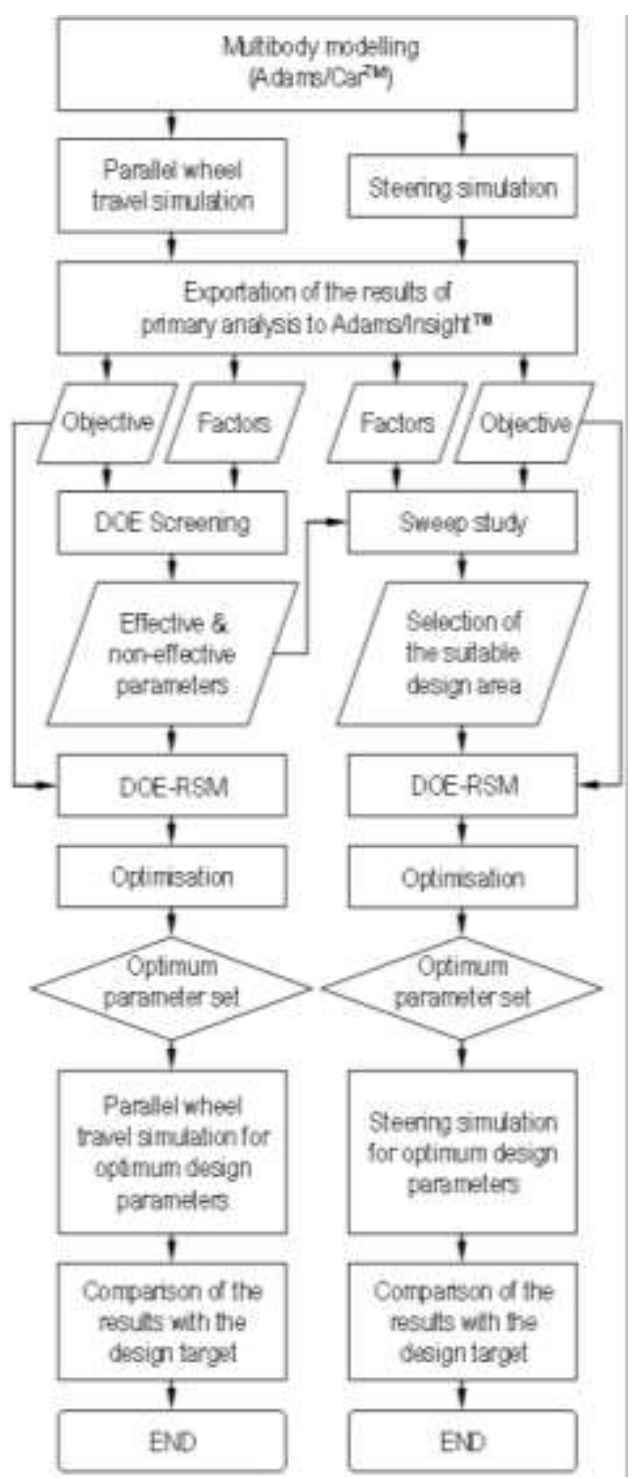

Fig. 8 Flow chart for the optimisation process

At the first stage, a primary simulation (parallel wheel travel or steering) is carried out by using the initial kinematic model generated in Adams/Car ${ }^{\mathrm{TM}}$. The design objective $\left(\beta_{V}\right.$ or $\left.\beta_{F}\right)$ is defined. Except for some differences, optimisation procedures for $\beta_{V}$ and $\beta_{F}$ are similar. Absolute value of the maximum deviation of the objective obtained from the primary simulation is imported to Adams/Insight ${ }^{\mathrm{TM}}$. The factors and design targets are also defined. In the light of the design constraints, the variation ranges of the factors are chosen. Effective and noneffective parameters are identified by screening experiments. Results obtained from these experiments are also used for the SS of $\beta_{F}$ optimisation. For the optimisation processes, investigation strategy is chosen as DOE-RSM. Number of the runs is determined according to the design type. The design space and workspace which contain the full set of the design trials and the results of their analyses are generated. Optimum set of the factors which gives the target value of the design objective is obtained by fitting the results to a polynomial or a response surface. In order to control the estimation results of the regression analysis, a multibody model which contains the optimum values of the factors is also carried out. Results obtained from this model are compared with the target value. Some steps of this flow chart have similar characteristics with the methodology given by [22] for the optimisation of the suspension parameters to improve impact harshness (IH) of road vehicles.

\section{Toe optimisation}

Fig. 9 shows the six total translational DOF of the hardpoints $\mathrm{A}_{9}$ and $\mathrm{A}_{10}$ which determine the position of the tie rod and directly affect the $\beta_{V}$ in case of wheel travel. Since tie rod is connected to the relay lever by the spherical joint $A_{10}$, initial position of the hardpoints $A_{13}$ and $A_{14}$ does not have any remarkable effect on $\beta_{V}$ for a given value of $\beta_{L}$. Hence, only the hardpoints of $\mathrm{A}_{9}$ and $\mathrm{A}_{10}$ are chosen as factors in stage 2 . A summary of the design limitations are also given in Fig. 10. Here $\mathrm{O}_{\mathrm{v}}$, the midpoint of the front axle was chosen as the reference point for this work. Appropriate positions of the hardpoints $A_{9}$ and $A_{10}$ were searched in the design volumes Cube 1 and Cube 2. Initial positions of the cubes and their edge lengths were chosen according to the design limitations which are summarised below. Position of $\mathrm{A}_{9}$ in $x$ axis should render possible enough space for wheel-end and brake system (Volume $B$ ) to eliminate any penetration of the mechanical elements. Initial value of $\mathrm{A}_{10 x}$ co-ordinate is chosen such that the mechanism should not be blocked in the $\beta_{L}$ range of the front wheels. As a design rule, the angles $\varphi$ and $\zeta$ between steering arm and tie rod should not be lower than $15^{\circ}[2]$ in

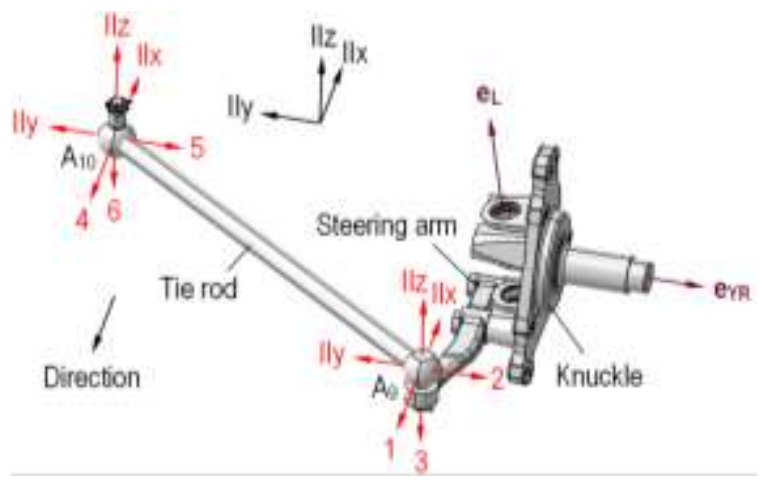

Fig. 9 Factors for $A_{9}$ and $A_{10}$ 
course of the maximum steering position of the front wheels as seen in Fig. 11.

Steel wheel limits the $-\mathrm{y}$ co-ordinate of $\mathrm{A}_{9}$ because of the installation issues. A gap " $e$ " is necessary which limits the $-y$ co-ordinate of $\mathrm{A}_{10}$ because of the installation issues. In this design, gap $e$ is assumed as $60 \mathrm{~mm}$ by considering the physical diameter of the spherical joint $\mathrm{A}_{10}$.

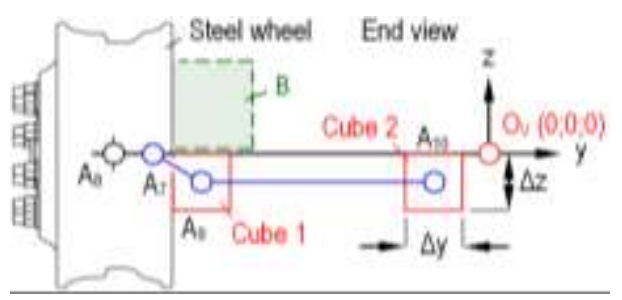

a

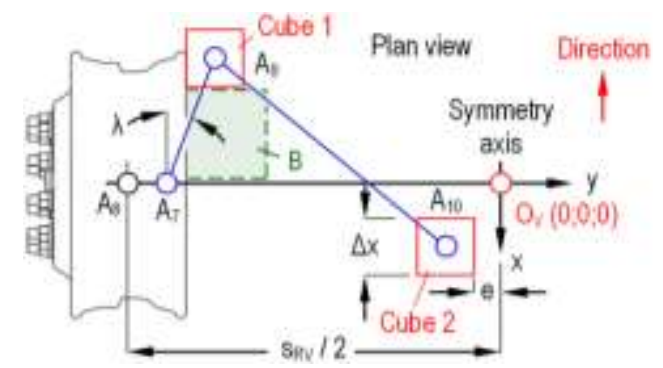

$\mathrm{b}$

Fig. 10 Summary of design limitations (schematic): a - end view, b - plan view

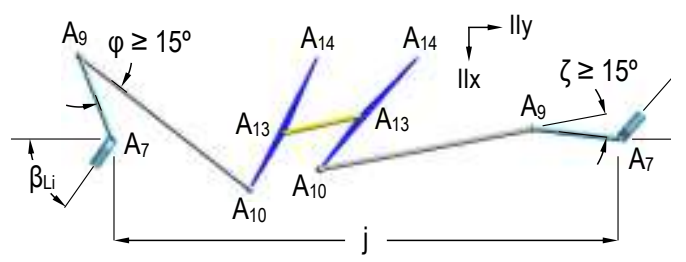

Fig. 11 Full left turn simulation

Because of the design issues, position of the steering arm - knuckle connection is lower than the wheel center $\mathrm{A}_{8}$ as seen from Fig. 12. Moreover, lower wishbone limits the vertical position of the tie rod. Hence, it is assumed that the vertical $(z)$ co-ordinates of $A_{9}$ and $A_{10}$ should be in the range of $z=(0-80) \mathrm{mm}$. For this assumption, brake system geometry is also taken into account. Design criterion was chosen such as the $\beta_{V}$ should not exceed $\pm 0.3^{\circ}$ in the wheel travel range of $\Delta z_{A 8}= \pm 100 \mathrm{~mm}$.

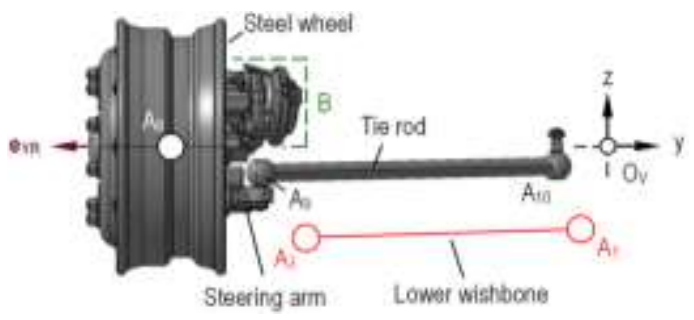

Fig. 12 Design limitations for brake system and wishbone

Before the optimisation process, DSA was applied to determine the effective and non-effective parameters among the tie rod factors on the response of the system. The two-level FFD type was chosen to generate the screen- ing experiments of the DSA, since it is the most proper type [22]. In this design type, only the lowest and the highest values of each factor are taken into account. As a rule, full factorial design provides $2^{n}$ runs for a single screen of experiments where $\mathrm{n}$ is the number of the factors. For $n=6$, FFD provides 64 trials (runs) which is considered as a reasonable experiment number. The results of the trials were fitted to a first order polynomial, whose general form is given in Eq. (5). Schematic of the design model can be seen in Fig. 13. Here, $A_{9}$ and $A_{10}$ (the red line) represent the chosen initial position of the tie rod. In Fig. 13, $A_{9 i}$ and $\mathrm{A}_{10 i}$ also stand for the $i$-th observation as an example (the green line). All of the possible design combinations which connect $A_{9}$ and $A_{10}$ were generated by Adams/Insight ${ }^{\mathrm{TM}}$ with the use of the cube edges. Successive simulations for every design combination were carried out. Length of the cube edges were chosen as $80 \mathrm{~mm}$.

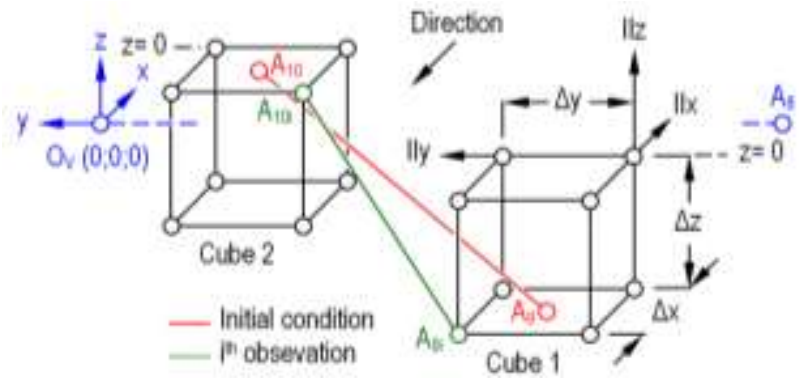

Fig. 13 Model for the tie rod position (schematic)

In order to determine the effects of the factors on $\beta_{V}$ clearly, results obtained from the 64 trials given in the design space were imported to MINITAB ${ }^{\circledR}$, statistical software. Design type was defined as custom factorial design. $\beta_{V}$ was also defined as the response of the analysis. The level of significance $\alpha$ was chosen as 0.01. Fig. 14 shows the Pareto chart of the standardised effects obtained from MINITAB ${ }^{\circledR}$ for the total 6 factors of $\mathrm{A}_{9}$ and $\mathrm{A}_{10}$. In this chart, only the main effects of the DOF's are taken into account. For $\alpha=0.01$, the threshold value was calculated as $u=2.665$. Since their standardised effects are greater that this limit, $\mathrm{A}_{9 z}$ and $\mathrm{A}_{10 z}$ are predicted as the factors which directly affect the $\beta_{V}$ during jounce and rebound. In order to test this result, the co-ordinate $\mathrm{A}_{9 x}$ which is the most effective factor under the u limit was solely altered in the range of $\pm 40 \mathrm{~mm}$. It was found that this alteration changed $\beta_{V}$ about $2.5 \%$ for $z_{A 8}=100 \mathrm{~mm}$ which can be considered as negligible effect.

Since it uses a first order polinomial type regression model, the two level factorial experiments based DSA

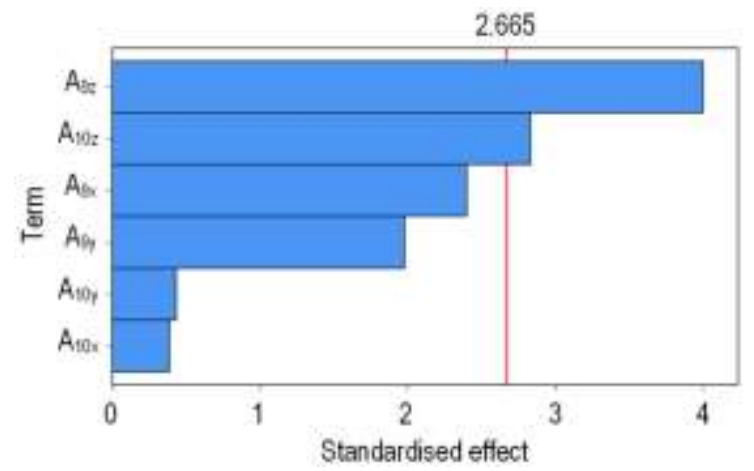

Fig. 14 Pareto chart of the standardised effects $(\alpha=0.01)$ 
does not give information about the possible curvature characteristic of the response. Hence, a second order polynomial model whose general form is given in Eq. (3) was utilised. CCD type that is offered in the design specification table of Adams/Insight ${ }^{\mathrm{TM}}$ was used to determine the optimum hardpoint locations of the tie rod. Total 50 runs were generated for the CCD process by the software. Optimal hardpoint co-ordinates of the tie rod obtained from Adams/Insight ${ }^{\mathrm{TM}}$ are compared with the initial model in Table 1 (for wheel 1). Parallel wheel travel simulation example of the IFS [23] for $\Delta \mathrm{z}_{\mathrm{A} 8}= \pm 100 \mathrm{~mm}$ is seen in Fig. 15.

Table 1

Initial and optimised hardpoint co-ordinates for tie rod

\begin{tabular}{|l|l|l|}
\hline Factor, mm & Initial & Optimised CCD \\
\hline A9 $x$ & -268 & -308 \\
\hline A9y & -795 & -755 \\
\hline A9 $z$ & -80 & -55.25 \\
\hline A10 $x$ & 200 & 240 \\
\hline A10y & -100 & -140 \\
\hline A10 $z$ & 0 & -42.4 \\
\hline
\end{tabular}

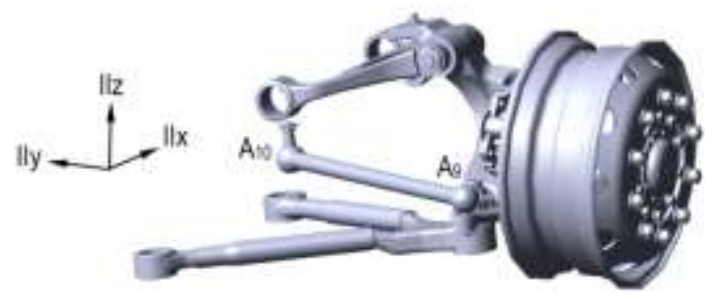

a

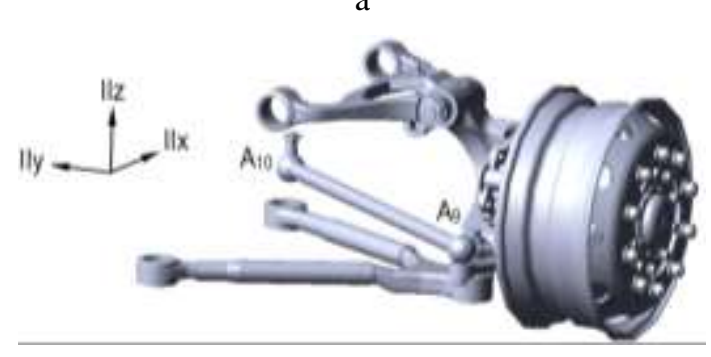

b

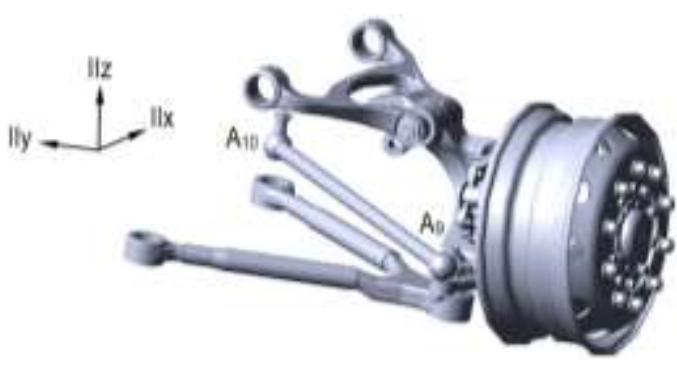

c

Fig. 15 Parallel wheel travel simulation of the IFS: $\Delta z_{A 8}=$ : $\mathrm{a}-+100 \mathrm{~mm}$; b - $0 \mathrm{~mm}$; c - $-100 \mathrm{~mm}$

Deviation characteristics of initial and optimised models are given in Fig. 16. Maximum $\beta_{V}$ values were obtained for $+100 \mathrm{~mm}$ bump and $-100 \mathrm{~mm}$ rebound of the wheel as $-0.26^{\circ}$ and $-0.32^{\circ}$ respectively.

In order to evaluate the interaction effects of the tie rod factors on $\beta_{V}$ deviation, the design matrix obtained from $\mathrm{CCD}$ was also imported to MINITAB ${ }^{\circledR}$. Fig. 17 shows the contour plots obtained from the software for the interactions of the design parameters where, the first term indicates the ordinate and the second is for abscissa.

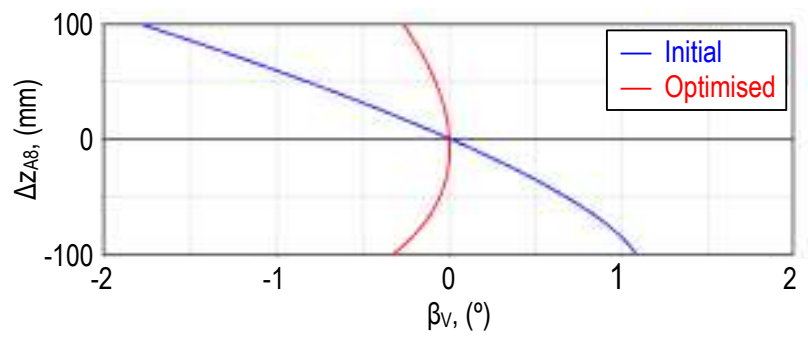

Fig. 16 Comparison of the $\beta_{V}$ deviation for initial and optimised designs
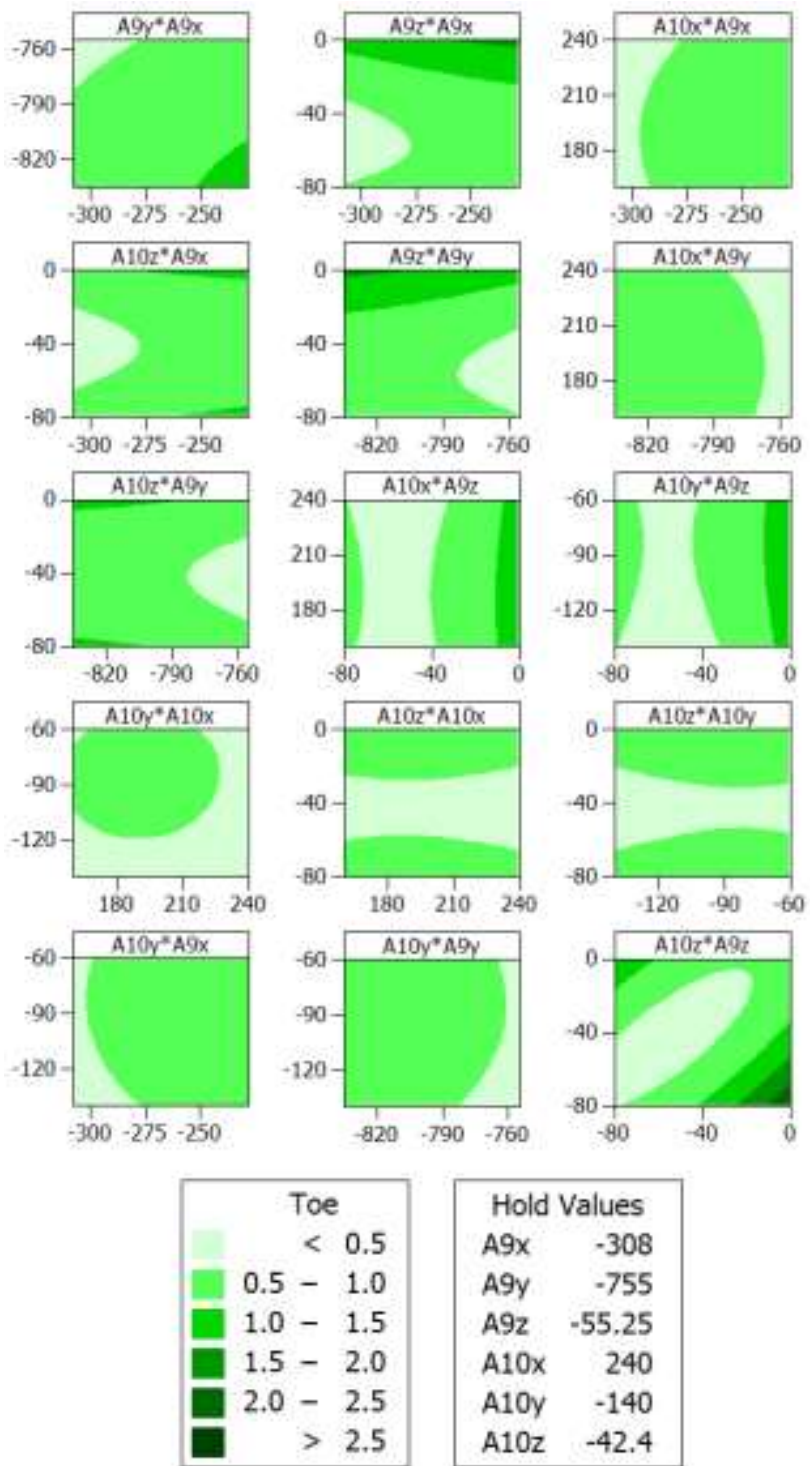

\begin{tabular}{lr}
\multicolumn{3}{c}{ Hold Values } \\
A9x & -308 \\
A9y & -755 \\
A9z & -55.25 \\
A10x & 240 \\
A10y & -140 \\
A10z & -42.4
\end{tabular}

Fig. 17 Contour plots for $\beta_{V}$

In order to obtain these plots, firstly, all of the factors were adjusted to their optimal values (hold values) obtained from CCD (Table 1). Then, only two of the factors were varied in the range of $\pm 40 \mathrm{~mm}$. As can be clearly seen from the contour plots, $\beta_{V}$ deviates strongly along the $A_{9 z}$ and $A_{10 z}$ axes. The response surface given in Fig. 18 which is identical to contour plot (A10 $\left.z^{*} \mathrm{~A} 9 z\right)$ also shows that $\mathrm{A}_{9 z}$ has a greater effect on the $\beta_{V}$ than $\mathrm{A}_{10 z}$. This result is compatible with the Pareto chart shown in Fig. 14. 


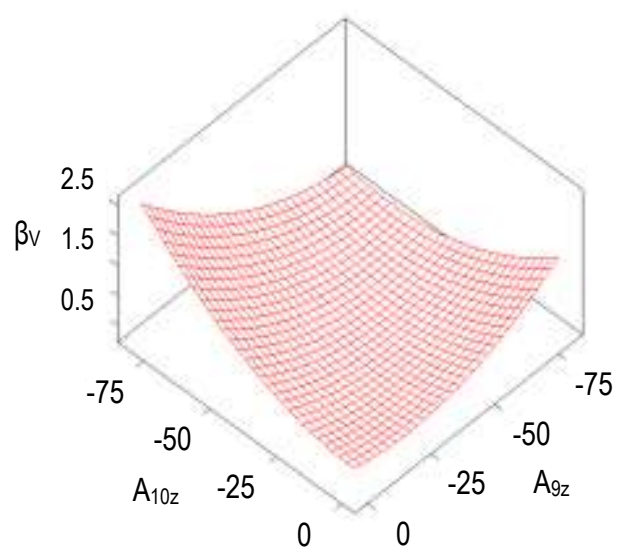

Fig. $18 \beta_{V}$ response as a function of $\mathrm{A}_{9 z}$ and $\mathrm{A}_{10 z}$

\section{Steering error optimisation}

Basic dimensions of the passenger bus used in this study are seen in Table 2. $\beta_{F}$ and $M S E$ values were obtained by taking these values as reference. Since a lower range of $\beta_{L}$ is used in most of the driving conditions of a passenger bus, minimising the $\beta_{F}$ for this range is acceptable $[10,11]$.

Basic dimensions of the passenger bus ( $\mathrm{mm}$ )

\begin{tabular}{|l|l|l|l|l|}
\hline$L_{F}$ & $L_{V}$ & $s_{R V}$ & $s_{R H}$ & $j$ \\
\hline 6050 & 3957 & 2096 & 1825 & 1844 \\
\hline
\end{tabular}

In this study, design criterion was chosen such as maximum steering error which is defined as:

$$
M S E=\max .\left|\beta_{L a}\left(\beta_{L i}\right)-\beta_{L a A}\left(\beta_{L i}\right)\right|
$$

should not be higher than $\pm 0.5^{\circ}$ in the range of $\beta_{L i}= \pm 20^{\circ}$. $M S E_{20}$ is the maximum steering error obtained in $\beta_{L i}= \pm 20^{\circ}$ range. Fig. 19 shows installation region of the steering system on the bus framework structure (area $C$ ) and the base model used in the third stage of this work respectively. In order to optimise $M S E$, an $\mathrm{H}$-shaped planar parallel arm mechanism which is consisted of two relay levers and a track rod was chosen as the base model.
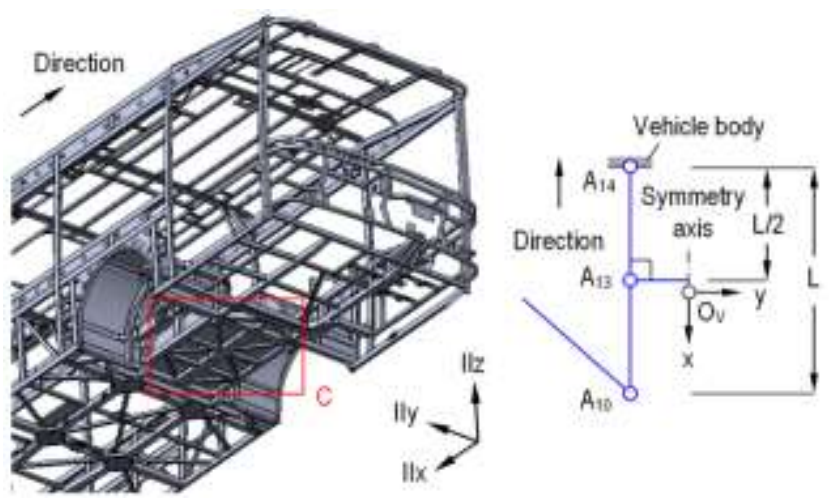

Fig. 19 Bus framework structure and the schematic $\mathrm{H}$-shaped base model for the optimisation study

In this model, initial position of the track rod was selected in the middle of the relay lever. The length $L$ of the relay lever in $\mathrm{x}$ axis is directly affects the overall steer- ing $i_{S}$ ratio which can be defined as:

$$
i_{S}=\frac{\beta_{S}}{\beta_{L}},
$$

where, $\beta_{S}$ is the steering wheel angle. In this study, possible range of $i_{S}$ was chosen in the range of 18-23 (-) due to the manufacturers demand. Effect of relay lever length on $i_{S}$ of the base mechanism can be seen as a function of $\beta_{S}$ in Fig. 20. $L_{1}$ was chosen as $540 \mathrm{~mm}$.

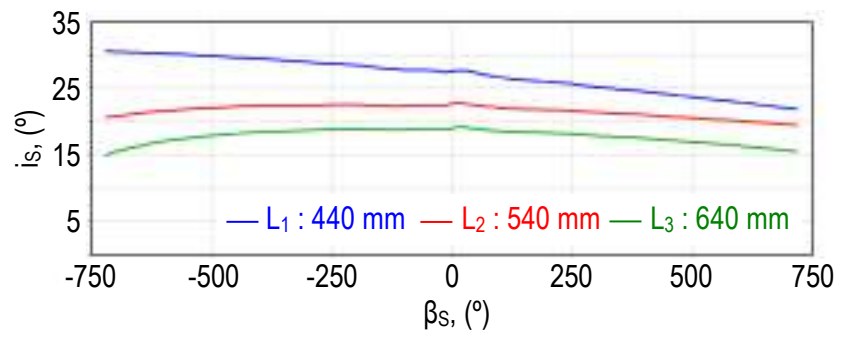

Fig. 20 Effect of the relay lever length on $i_{S}$

Design schematic of the relay lever-vehicle body connection is illustrated upside down in Fig. 21. Here, the longitudinal rails $M$ are welded to the lateral rail $N$ on which the bearing of $\mathrm{A}_{14}$ is located. In order to find out the appropriate design range for optimisation of the relay lever, a pre-study includes the SS option of Adams/Insight ${ }^{\mathrm{TM}}$ was carried out. In this type of design study, the possible range of a factor is determined by taking the design limitations into account. The chosen number of runs specifies how the factor interval will be divided [21]. Results of the runs give an estimation for the deviation characteristic of the $M S E_{20}$ response.

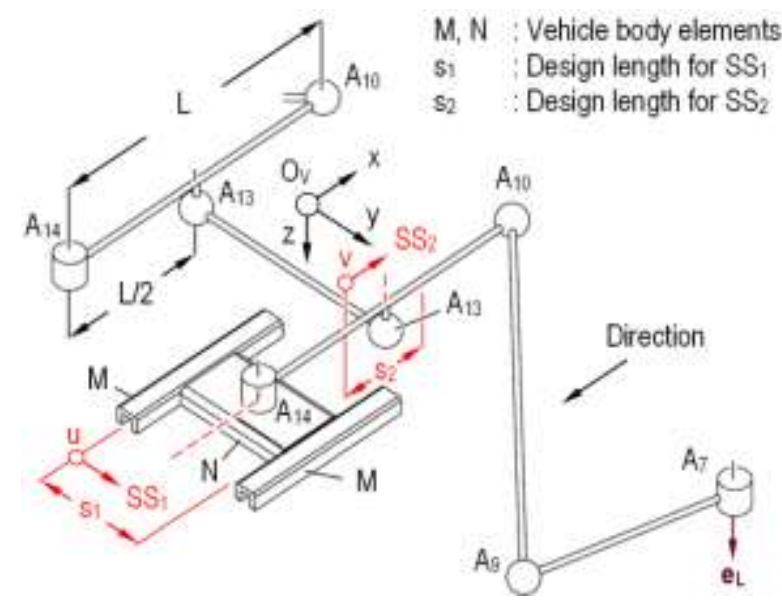

Fig. 21 Design detail of the vehicle body-relay lever connection

In this work, $\mathrm{SS}$ is performed in two successive steps: Primary position of $\mathrm{A}_{10}$ was assumed as fixed in $\mathrm{x}-\mathrm{y}$ plane. Position of hardpoint $\mathrm{A}_{14}$ was changed in $\mathrm{y}$ axis in the range of $\pm 50 \mathrm{~mm}$. Dimensions of the rails on which relay lever attached via $\mathrm{A}_{14}$ bearings were taken into account to determine this design limit. In Fig. 21, u represents the initial trial point of the $\mathrm{SS}_{1}$. Step size was chosen as $5 \mathrm{~mm}$ for the total $s_{1}=100 \mathrm{~mm}$ design length. 21 trials were generated. As can be seen from the convergence history of $\mathrm{SS}_{1}$ shown in Fig. 22, minimum value of $M S E_{20}$ was obtained at trial 19 as $M S E_{20}=0.525^{\circ}$. Here, trial 11 represents the base model. In the subsequent step, hard- 
point $\mathrm{A}_{14}$ was adjusted to the minimum value obtained from $\mathrm{SS}_{1}$. Then, the planar position of track rod was altered only in $x$ axis in the range of $\pm 50 \mathrm{~mm}$. Step size was also chosen as $5 \mathrm{~mm}$ for the total $s_{2}=100 \mathrm{~mm}$ design length. For $\mathrm{SS}_{2}, 21$ trials were generated where $\mathrm{v}$ represents the initial trial point. Convergence history of the $S S_{2}$ shows that (Fig. 22) trial 10 provides an estimated optimum value of $M S E_{20}$ which is calculated as $0.524^{\circ}$. All of the trials of $\mathrm{SS}_{1}$ and $\mathrm{SS}_{2}$ were analysed for $\beta_{S}=+420^{\circ}$ which correponds to $i_{S} \approx 21$ and $\beta_{L i} \approx 20^{\circ}$.

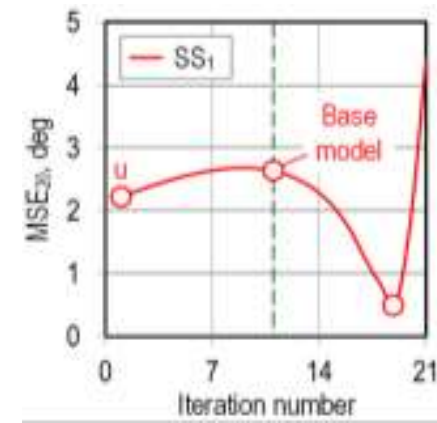

a

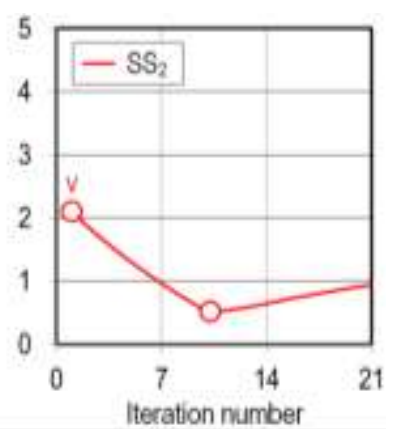

b
Fig. 22 Convergence histories for: $\mathrm{a}-\mathrm{SS}_{1} ; \mathrm{b}-\mathrm{SS}_{2}$

Since the main target of the $\mathrm{SS}_{1}$ and $\mathrm{SS}_{2}$ is to predict the reasonable design range of the hardpoints for the multi-link mechanism, results obtained from these studies are rough. These results were used to perform a final optimisation process using CCD. According to research [23], $\lambda$ angle (Fig. 11) also affects the steering error. Because of this, $A_{9 x}$ and $A_{9 y}$ should also be taken into account for the $\mathrm{CCD}$ study. Hence, $\mathrm{A}_{9}, \mathrm{~A}_{10}, \mathrm{~A}_{13}$ and $\mathrm{A}_{14}$ were chosen as the design variables. On the other hand, in order not to increase the $\beta_{V}$ deviation during the wheel travel, all of the factors cannot be used for the optimisation process. As can be seen from the Pareto chart in Fig. 14, $\mathrm{A}_{10 x}$ and $\mathrm{A}_{10 y}$ which have lower standardised effects than $u=2.665$ can be chosen as design variables for the relay lever. Because of the planarity of the mechanism, $\mathrm{A}_{13 z}$ and $\mathrm{A}_{14 z}$ were assumed as equal to $\mathrm{A}_{10 z}$ obtained from CCD. Variation range of the factors was chosen in $x-y$ plane as $\pm 10 \mathrm{~mm}$ except $A_{9 x}$ and $A_{13 x}$. In order to shorten the design length of the steering arm, design constraint for $\mathrm{A}_{9 x}$ was selected as $(0-40) \mathrm{mm}$. It is known from Pareto chart that this alteration does not have any remarkable effect on the $\beta_{V}$ angle. $\mathrm{A}_{13 \mathrm{x}}$ range was also selected as $(0-30) \mathrm{mm}$ to increase the rigidity of the frame. By using CCD option of Adams/Insight ${ }^{\mathrm{TM}} 88$ trials were generated by the software for 8 factors. Convergence history can be seen in Fig. 23 where minimum $M S E_{20}$ was obtained as $\approx 0.2^{\circ}$. By using the optimal hardpoint co-ordinates obtained from Adams/Insight ${ }^{\mathrm{TM}}$ which are compared with the base model in Table 3, a final multibody model was composed and analysed via Adams/Car ${ }^{\mathrm{TM}}$.

Comparison of the base and optimal multi-link model geometries is seen in Fig. 24. It was found that, for the optimised model, $\zeta$ angle between tie rod and steering arm satisfies $\zeta \geq 15^{\circ}$ condition. $\zeta$ was obtained as $\zeta \approx 20^{\circ}$ for $\beta_{L i}=55^{\circ}$ which portrayes the extreme steering condition. For the optimal design, the angle between the line $\left|\mathrm{A}_{10}-\mathrm{A}_{14}\right|$ and the $x$ axis was calculated as $\xi_{\text {opt }} \approx 4.5^{\circ} . M S E_{20}$ was achieved as $0.34^{\circ}$.

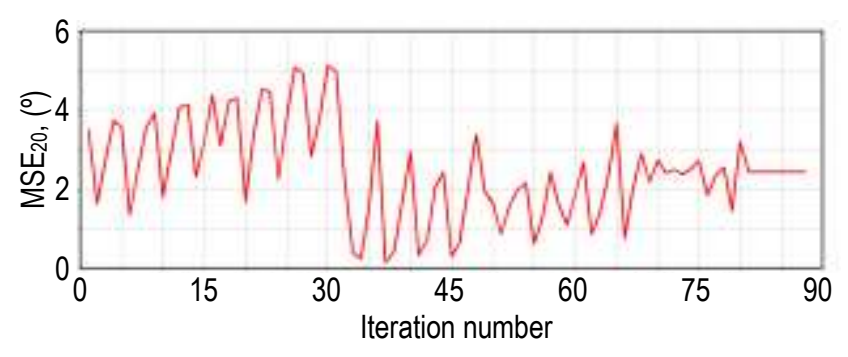

Fig. 23 Convergence history of CCD (estimations)

Table 3

Hardpoint co-ordinates of base and optimised models

\begin{tabular}{|l|l|l|}
\hline Factor $(\mathrm{mm})$ & Base & Optimised CCD \\
\hline A9x & -308 & -270.7 \\
\hline A9y & -755 & -746.49 \\
\hline A10x & 240 & -240.83 \\
\hline A10y & -140 & -140.3 \\
\hline A13x & -28.5 & -1.9 \\
\hline A13y & -140 & -140.41 \\
\hline A14x & -300 & -296.32 \\
\hline A14y & -140 & -182.77 \\
\hline
\end{tabular}

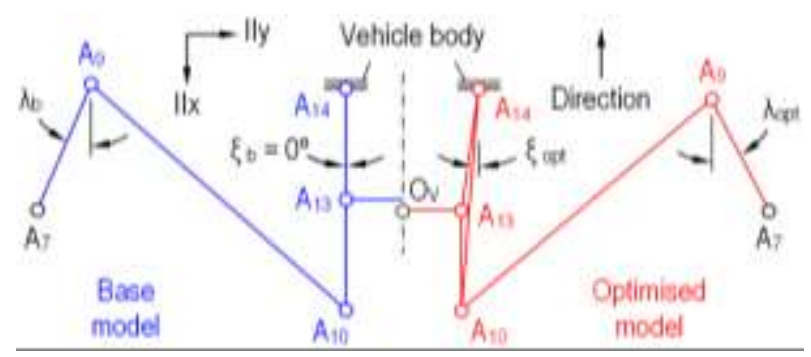

Fig. 24 Comparison of the base and optimised geometries

Obtained minimum values and percent reductions of $M S E_{20}$ after every step of the optimisation study are given in Table 4 and in Fig. 25 respectively. In Fig. 25, a. the estimated $M S E_{20}$ values for $\mathrm{SS}_{1}, \mathrm{SS}_{2}$ and CCD are compared with $\beta_{F}\left(\beta_{L i}\right)=2.22^{\circ}$ that is also obtained from the base model for $\beta_{L i}=20^{\circ}$.

Table 4

Estimated and obtained $M S E_{20}$ values $\left(\beta_{L i} \approx 20^{\circ}\right)$

\begin{tabular}{|l|l|l|l|l|}
\hline \multicolumn{2}{|l|}{ Estimations } & Final model & Design target \\
\cline { 1 - 3 }$S S_{1}$ & $S S_{2}$ & $C C D$ & \multirow{2}{*}{$0.34^{\circ}$} & $\leq \pm 0.5^{\circ}$ \\
\cline { 1 - 2 } $0.525^{\circ}$ & $0.524^{\circ}$ & $0.2^{\circ}$ & & \\
\hline
\end{tabular}

In order to calculate the percent reduction, $M S E_{20}$ of the base model was assumed as $100 \%$. As can be seen from Fig. 25, a, $M S E_{20}$ dramatically decreases after $\mathrm{SS}_{1}$ where the reduction was calculated as $80.1 \%$ in comparison with the base model. MSE reduction after $\mathrm{SS}_{2}$ and CCD were also calculated as $0.04 \%$ and $12.3 \%$ respectively. Hence, it can be concluded that the most effective factor on $M S E_{20}$ reduction is $\mathrm{A}_{14 y}$ or the $\xi$ angle. Additionally, it should be noted that the calculated $M S E_{20}$ obtained from $\mathrm{SS}_{1}, \mathrm{SS}_{2}$ and CCD are the estimated values. $M S E_{20}$ provided from the multibody analyses of base and final optimised models are also given in Fig. 25, b. Total reduction of $M S E_{20}$ was obtained as $84.8 \%$.

Ackermann error deviations of the base and the optimised models as a function of $\beta_{L i}$ are given in Fig. 26. As also can be seen that $M S E$ achieved from the final op- 
timised model is $0.46^{\circ}$ at $\beta_{L i}=30^{\circ}$ in the range of $\beta_{L i}=\left(0-44^{\circ}\right)$ which exceedingly satisfies the design target. For instance, by using Eq. (1) $\beta_{L i}$ is calculated as $33.14^{\circ}$ for $R_{0 \min }=10.4 \mathrm{~m}$, the minimum turning radius of the passenger bus and the dimensions given in Table 2. Steering error of the base mechanism was obtained for $\beta_{L i}=30^{\circ}$ as $4.4^{\circ}$ which means the reduction by $89.6 \%$.

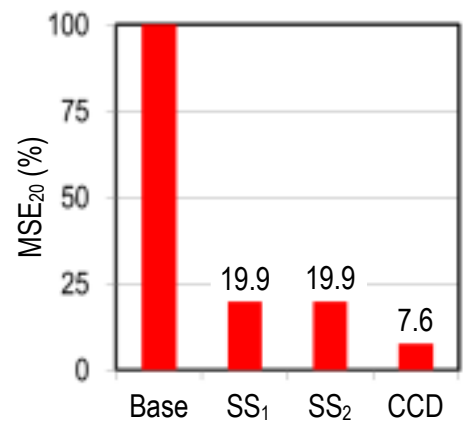

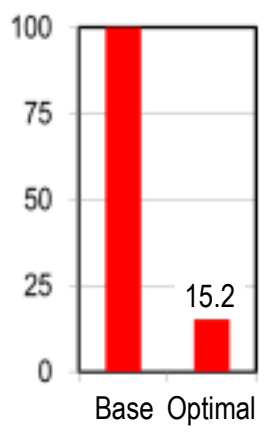

$\mathrm{b}$
Fig. 25 Reduction of $M S E_{20}$ : a-estimations during the optimisation stages; $b$ - comparison of base and optimised models

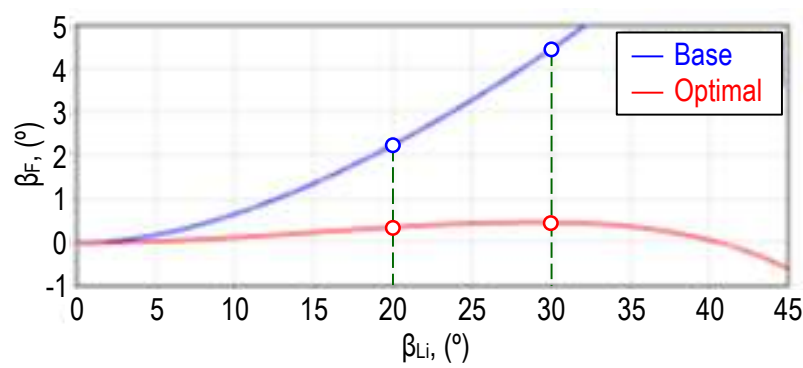

Fig. 26 Comparison of the $\beta_{F}\left(\beta_{L i}\right)$ curves for base and optimised models

\section{Conclusions}

In this work, a DOE-RSM based design application to obtain a multi-link steering mechanism which gives optimum deviation of $\beta_{V}$ and steering error was developed and applied on an MSC.Adams ${ }^{\circledR}$ multibody model of a bus IFS. In order to carry out the optimisation of the $\beta_{V}$, the most effective parameters among the tie rod co-ordinates on $\beta_{V}$ deviation were first identified via DSA by using Adams/Insight ${ }^{\mathrm{TM}}$ multi-objective optimisation tool. The FFD was used to determine the rank of importance of the coordinates of the tie rod hardpoints on $\beta_{V}$ angle. Results were evaluated by using MINITAB ${ }^{\circledR}$ a practical statistical software package. Since the FFD merely uses the high and low values of the factors, it is not adequate to determine the possible curvature of the response. In order to find out the intermediate values of the parameters which give the optimal tie rod position, CCD was also applied. In the final stage of the study, geometry of the steering trapezoid which gives the optimum MSE was determined via SS and $\mathrm{CCD}$. In order to do that the co-ordinate $\mathrm{A}_{10 z}$ was assumed as the design constraint which determines the vertical position of the multi-link mechanism plane. Results obtained from this study are summarised as follows:

1. Results of the DSA showed that for a multi-link steering mechanism, the most effective factors among the tie rod co-ordinates on $\beta_{V}$ are the vertical components $\mathrm{A}_{9 z}$ and $\mathrm{A}_{10 z}$. For this design example, percent effects of $\mathrm{A}_{9 z}$ and $\mathrm{A}_{10 z}$ were calculated as $44.71 \%$ and $31.76 \%$ respectively. CCD gives the optimum values of these coordinates more precisely than the FFD with a fewer number of design trials.

2 . By using $\mathrm{CCD}, \beta_{V}$ deviation during the wheel travel was reduced up to $85.4 \%$ in comparison with the initial design. Maximum $\beta_{V}$ values were obtained for +100 $\mathrm{mm}$ bump and $-100 \mathrm{~mm}$ rebound of the wheel as $-0.26^{\circ}$ and $-0.32^{\circ}$ respectively.

3. By optimizing the shape of the relay lever, $M S E$ of the initial parallel arm (H-shaped) base mechanism was reduced up to $89.6 \%$ via $\mathrm{SS}_{1}, \mathrm{SS}_{2}$ and $\mathrm{CCD}$ in the range of $\beta_{L i}= \pm 44^{\circ}$. It is observed that the most effective part of the estimation analyses on $M S E$ reduction is $\mathrm{SS}_{1}$. By this way it can be concluded that co-ordinate $\mathrm{A}_{14 y}$ (or the angle $\xi$ ) has the greatest effect on MSE. In this design, effect of $S_{2}$ can be assumed as negligible.

4. The obtained optimal mechanism satisfies the design target of $M S E \leq \pm 0.5^{\circ}$ in the range of $\beta_{L i}= \pm 44^{\circ}$. Moreover, the mechanism can perform its function up to $\beta_{L i}=55^{\circ}$ without any lock up effect.

\section{Acknowledgements}

The authors are grateful for the suggestions of Prof. N. S. Kuralay, Ph.D. of Dokuz Eylül University, Department of Mechanical Engineering. The licensed software support of Hexagon Studio is also acknowledged.

\section{References}

1. Timoney, E.; Timoney S. 2003. A review of the development of independent suspension for heavy vehicles, 2003 SAE International Truck and Bus Meeting and Exhibition, SAE Technical Paper 2003-01-3433. http://dx.doi.org/10.4271/2003-01-3433.

2. Reimpell, J. 1974. Fahrwerktechnik, Bd. 3, Würzburg: Vogel-Verlag, 177p.

3. Reimpell, J.; Stoll, H.; Betzler, J.W. 2002. The Automotive Chassis: Engineering Principles, Warrendale, PA.: Society of Automotive Engineers, Inc.

4. Simionescu, P.A.; Beale, D. 2002. Optimum synthesis of the four-bar function generator in its symmetric embodiment: the Ackermann steering linkage, Mechanism and Machine Theory 37(12): 1487-1504. http://dx.doi.org/10.1016/S0094-114X(02)00071-X.

5. Zhou, B.; Li, D.; Yang, F. 2009. Optimization design of steering linkage in independent suspension based on genetic algorithm, IEEE 10th International Conference on Computer-Aided Industrial Design \& Conceptual Design: CAID\&CD. Wenzhou, 45-48p. http://dx.doi.org/10.1109/CAIDCD.2009.5374895.

6. Hanzaki, A.R.; Rao, P.V.M.; Saha, S.K. 2009. Kinematic and sensitivity analysis and optimization of planar rack-and-pinion steering linkages, Mechanism and Machine Theory 44(1) 42-56. http://dx.doi.org/10.1016/j.mechmachtheory.2008.02.0 14.

7. Oz, Y.; Ozan, B.; Uyanik, E. 2012. Steering system optimization of a Ford heavy-commercial vehicle using kinematic \& compliance analysis, SAE Technical Paper 2012-01-1937.

http://dx.doi.org/10.4271/2012-01-1937. 
8. Liang J.; Xin, L. 2012. Simulation analysis and optimization design of front suspension based on ADAMS, Mechanika 18(3): 337-340.

http://dx.doi.org/10.5755/j01.mech.18.3.1873.

9. Kim, B.; M., Kim, J.W.; Moon, I.D.; Oh, C.Y. 2014. Optimal combination of design parameters for improving the kinematics characteristics of a midsize truck through design of experiment, Journal of Mechanical Science and Technology 28(3): 963-969. http://dx.doi.org/10.1007/s12206-013-1167-7.

10. Bian, X.L.; Song, B.A.; Becker, W. 2003. The optimisation design of the McPherson strut and steering mechanism for automobiles, Forschung im Ingenieurwesen 68(1): 60-65. http://dx.doi.org/10.1007/s10010-003-0107-6.

11. Bian, X.L.; Song, B.A.; Walter, R. 2004. Optimization of steering linkage and double wishbone suspension via R-W multibody dynamic analysis, Forschung im Ingenieurwesen 69(1): 38-43. http://dx.doi.org/10.1007/s10010-004-0136-9.

12. Minitab User's Guide 1: Data Graphics and Macros (Release 13 for Windows), 1999. Pennsylvania State University, USA.

13. MSC.Adams ${ }^{\circledR}$. 2002. Product Catalog. MSC. Software Corporation.

14. Blundell, M.; Harty, D. 2006. The Multibody Systems Approach to Vehicle Dynamics, London: Elsevier Butterworth - Heinemann, 172p.

15. Matschinsky, W. 2007. Radführungen der Straßenfahrzeuge. 3. aktualisierte und erweiterte Auflage, Berlin Heidelberg: Springer-Verlag, 96, 97p.

16. Kuiper, E.; Van Ooster, J.J.M. 2007. The PAC2002 advanced handling tire model, Vehicle System Dynamics: International Journal of Vehicle Mechanics and Mobility, 45(1): 153-167. http://dx.doi.org/ 10.1080/00423110701773893.

17. Montgomery, D.C. 2000. Design and analysis of experiments. Fifth Edition, Hoboken, New Jersey: John Wiley \& Sons, Inc. 275p.

18. Park, K.; Heo, S.J.; Kang, D.O.; Jeong, J.I.; Yi, J.H.; Lee, J.H.; Kim, K.W. 2013. Robust design optimization of suspension system considering steering pull reduction, International Journal of Automotive Technology 14(6): 927-933. http://dx.doi.org/10.1007/s12239-013-0102-3.

19. Han, H.; Park, T. 2004. Robust optimal design of multi-body systems, Multibody system dynamics 11(2): 167-183. http://dx.doi.org/10.1023/B:MUBO.0000025414.28789 34 .

20. Myers, R.H.; Montgomery, D.C.; Anderson-Cook, C.M. 2009. Response Surface Methodology: Process and Product Optimization Using Design of Experiments, Third Edition. Hoboken, New Jersey: John
Wiley \& Sons, Inc. 704 p.

21. MSC.ADAMS ${ }^{\circledR}$. 2013. ADAMS/Insight ${ }^{\mathrm{TM}}$ User Guide. MSC. Software Corporation.

22. Aydın, M.; Ünlüsoy, S. 2012. Optimization of suspension parameters to improve impact harshness of road vehicles, The International Journal of Advanced Manufacturing Technology 60(5-8): 743-754. http://dx.doi.org/10.1007/s00170-011-3589-7.

23. Genta, G. 1997. Motor Vehicle Dynamics, Singapore: World Scientific Publishing Co. Pte. Ltd., Regal Pres (S) Pte. Ltd. 216p.

M. M. Topaç, U. Deryal, E. Bahar, G. Yavuz

OPTIMAL KINEMATIC DESIGN OF A MULTI-LINK STEERING SYSTEM FOR A BUS INDEPENDENT SUSPENSION: AN APPLICATION OF RESPONSE SURFACE METHODOLOGY

S u m m a r y

A response surface-based design application to obtain an optimum multi-link steering mechanism is presented. Design problem is essentially established on two main goals: minimum deviation of toe angle $\left(\beta_{V}\right)$ during the wheel travel and optimum steering error during the steering angle $\left(\beta_{L}\right)$ range of the wheel. In the first stage, a complete multibody model of the suspension system including the steering mechanism was composed by using MSC.Adams ${ }^{\circledR}$ software. In order to identify the most effective parameters among the tie rod co-ordinates on $\beta_{V}$ deviation, a Full Factorial Design (FFD) - based Design Sensitivity Analysis (DSA) was carried out via Adams/Insight ${ }^{\mathrm{TM}}$ multi-objective optimisation tool. Central Composite Design (CCD) was also implemented to find out the optimum position of the tie rod. In the final stage, optimum hardpoint positions of the steering mechanism were searched by a combination of sweep study (SS) and CCD to provide the minimum deviation of Ackermann error. The optimisation results show that it is possible to reduce the maximum steering error (MSE) of the system up to $89.6 \%$ in comparison with the parallel arm base mechanism by using the proposed methodology.

Keywords: Ackermann steering, central composite design (CCD), design of experiments (DOE), independent front suspension (IFS), maximum steering error (MSE), multilink steering system, optimisation, regression, response surface methodology (RSM).

Received April 17, 2015

Accepted June 23, 2015 